\title{
PRESSURE DRAWDOWN AND BUILD-UP ANALYSES IN GEOTHERMAL RESERVOIRS
}

\author{
LARRY F. RICE
}

IR\&D PROJECT 93102-02

MARCH 1976

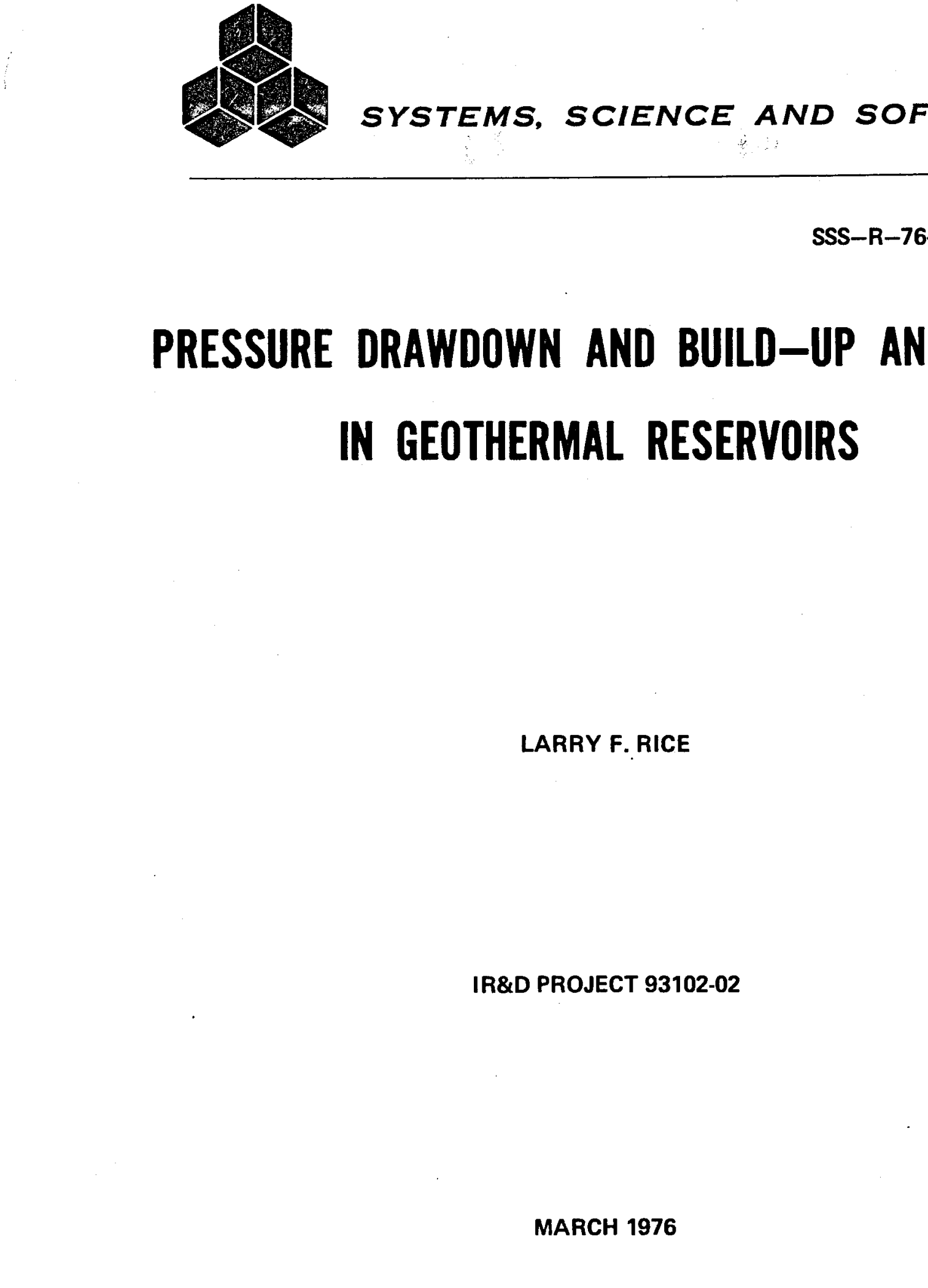




\section{DISCLAIMER}

This report was prepared as an account of work sponsored by an agency of the United States Government. Neither the United States Government nor any agency Thereof, nor any of their employees, makes any warranty, express or implied, or assumes any legal liability or responsibility for the accuracy, completeness, or usefulness of any information, apparatus, product, or process disclosed, or represents that its use would not infringe privately owned rights. Reference herein to any specific commercial product, process, or service by trade name, trademark, manufacturer, or otherwise does not necessarily constitute or imply its endorsement, recommendation, or favoring by the United States Government or any agency thereof. The views and opinions of authors expressed herein do not necessarily state or reflect those of the United States Government or any agency thereof. 


\section{DISCLAIMER}

Portions of this document may be illegible in electronic image products. Images are produced from the best available original document. 
SSS-R-76-2845

\section{PRESSURE DRAWDOWN AND BUILD-UP ANALYSES IN GEOTHERMAL RESERVOIRS}

LARRY F. RICE

IR\&D PROJECT $93102-02$

MARCH 1976 
TABLE OF CONTENTS

Page

ABSTRACT . . . . . . . . . . . ... 1

I. BACKGROUND . . . . . . . . . . 2

II. ONE-DIMENSIONAL EXAMPLES . . . . . . . 5

2.1 EXAMPLE I. ONE-DIMENSIONAL, SINGLE-

PHASE • • . . . . . . . . . . 5

2.1.1 Drawdown ......... 5

2.1 .2 Build-Up . . . . . . . 5

2.2 EXAMPLE II. ONE-DIMENSIONAL, TWO

PHASE . . . . . . . . . . 8

2.2.1 Drawdown ........ 8

2.2 .2 Build-Up . . . . . . 8

III. TWO-DIMENSIONAI EXAMPLES . . . . . . 12

3.1 EXAMPIE I. TWO DIMENSIONS, SINGLE-

PHASE ................ 12

3.1.1 Drawdown . . . . . . 12

3.1 .2 Build-Up . . . . . . . 12

3.2 EXAMPLE II. TWO DIMENSIONS, TWO

PHASES . . . . . . . . . 16

3.2 .1 Drawdown ........ 16

3.2 .2 Build-Up . . . . . . 16

IV. VAPOR BUOYANCY . . . . . . . . . . 19

v. CONCLUSION . . . . . . . . . . . 24 


\section{ABSTRACT}

Classical well analyses were performed using systems, Science and Software's Quasi-Active Geothermal Reservoir simulator (QUAGMR). QUAGMR solves the equations of heat flow and unsteady Darcian fluid flow in one, two, or three space dimensions. The computer model is capable of handing a single-phase liquid-water system or a multiphase liquid/ vapor system.

Pressure drawdown and build-up well-tests are performed to acquire permeability data for the reservoir. Classical well-test interpretation assumes that only a single phase is flowing during the test. This assumption can lead to dramatic errors in the permeability data if, in fact, there is multiphase flow during the test.

Several calculations were performed which demonstrate these errors in interpretation. A suite of four problems is presented to illustrate these results. One and two-dimensional problems were formulated with single and multiphase flow during the well-test. In the single phase problems, very good agreement with the classical theory was obtained. However, in the multiphase problems, the classical interpretation led to gross errors in the permeability data.

These results indicate the need for a simulator which will handle multiphase flow in a geothermal system. without this capability, errors in the interpretation of well flow data could lead to mismanagement of the reservoir engineering of the geothermal field. 


\section{BACKGROUND}

Pressure drawdown and build-up experiments are welltests which are performed to obtain permeability data for the reservoir formation.

For a drawdown test, a well, initially at equilibrium conditions, is produced at a constant flow rate while the bottom hole pressure history is recorded. After the well has been produced in this manner, a pressure build-up test is often performed...by shutting-in the well (1.e., by discontinuing any production from the well) and again monitoring the bottom hole pressure as the reservoir equilibrates.

Classical well-test interpretation assumes a singlephase flow in the reservoir. Using this classical interpretation, the above described pressure histories are used to "back-out" the effective permeability of the reservoir. It will be shown in the following examples that if, in fact, there is only single-phase flow in the reservoir, very good agreement exists between the classical well-test interpretation and the results of our computer simulation. However, if this single-phase interpretation is used, when in fact there is multiphase flow in the reservoir, the examples aramatically illustrate that gross errors in the derived permeability data may be obtained. Thus, in order to interpret the reservoir behavior during multiphase flow, it is necessary to have a simulator which can accurately handle this multiphase behavior. $S^{3}$ 's QUasi-Active Geothermal Reservoir Model (QUAGMR) is such a simulator. It was used to perform the following calculations.

Theory

The analytic solution for single-phase radial flow is 
given by

$$
p(r, t)=p_{i}+\frac{q u}{4 \pi h k} \ln \left(\frac{\gamma \phi \mu c r^{2}}{4 k t}\right)
$$

where the units are Darcy units, i.e.,

$$
\begin{array}{ll}
p(r, t) & =\text { Pressure at time } t \text { and radius } r \text {, atm. } \\
p_{i} & =\text { Initial pressure of the reservoir, atm. } \\
q & =\text { Flow rate in cc/sec } \\
\mu & =\text { Viscosity in cp } \\
h & =\text { Reservoir thickness in cm } \\
k & =\text { Permeability in darcies } \\
r & =\text { Euler's constant, } 1.78 \\
\phi \quad & =\text { Porosity of the reservoir } \\
c & =\text { Compressibility in cc/cc/atm } \\
r \quad & =\text { Radius in cm } \\
t \quad & =\text { Time in sec. }
\end{array}
$$

Differentiating the above expression for $p(r, t)$ with respect to $\ln t$ we get

$$
\frac{\partial p}{\partial \ln t}=-\frac{q \mu}{4 \pi k h}
$$

Converting this expression to the units described below and $\log _{10} t$, we get

$$
\frac{\partial p}{\partial \log _{10} t}=-\frac{(2.30)(1.01325)(1000) q \mu}{4 \pi k h p}
$$

where

$$
\begin{aligned}
& p=\text { Pressure in bars } \\
& t=\text { Time in sec }
\end{aligned}
$$




$$
\begin{aligned}
& q=\text { Flow rate in } \mathrm{gm} / \mathrm{sec} \\
& \mu=\text { Viscosity in } \mathrm{cp} \\
& \mathrm{k}=\text { Permeability in md } \\
& \mathrm{h}=\text { Reservoir thickness in } \mathrm{cm} \\
& \rho=\text { Density in } \mathrm{gm} / \mathrm{cc}
\end{aligned}
$$

The constants $2.30,1.01325$, and 1000 are conversion factors from Darcy units to the above unit system.

The above expression for $\partial p / \partial\left(\log _{10} t\right)$ tells us that the graph of pressure versus $\log _{10} t$ should be linear. If we plot the drawdown pressure history versus $\log _{10} t$, find the slope of the best straight-line approximation to the plotted curve, and then equate the value of the slope to the righthand side of Eq. (3), we can "back-out" the permeability of the reservoir since we know all the other values on the right-hand side of the equation.

For a pressure build-up analysis, the following equation is used to determine the effective permeability

$$
\frac{\partial p}{\partial \log _{10} t_{s}} \approx \frac{(2.30)(1.01325)(1000) q \mu}{4 \pi k h p}
$$

where $t_{s}$ is the shut-in time in seconds, i.e., time after production was terminated.

The following examples illustrate these techniques. 


\section{ONE-DIMENSIONAL EXAMPLES}

The examples below are one-dimensional axisymetric problems with 25 uniform-sized computational zones (see Fig. 1). Pressure and energy fluxes are prescribed at the outer boundary. The zone nearest the axis of symmetry is a mass sink. The following properties are used for the calculations:

Porosity $=0.1$

Rock Grain Density $=2.65 \mathrm{gm} / \mathrm{cc}$

Rock Thermal Conductivity $=2.1 \times 10^{3} \mathrm{ergs} / \mathrm{sec}-\mathrm{cm}-{ }^{\circ} \mathrm{K}$

Rock Heat Capacity $=1.0 \times 10^{7}$ ergs $/ \mathrm{gm}^{\circ}{ }^{\circ} \mathrm{K}$

Residual Liquid Saturation $=0.3$

Residual vapor Saturation $=0.05$

Permeability $=3$ md

2.1 EXAMPLE I. ONE-DIMENSIONAL, SINGLE-PHASE

\subsubsection{Drawdown}

Initial pressure of the reservoir $=124.98$ bars

Initial temperature of the reservoir $=586^{\circ} \mathrm{K}$

Mass sink production rate $=0.414 \mathrm{gm} / \mathrm{sec}$

Figure 2 is the plot of the drawdown pressure computed by the QUAGMR code in the sink zone versus $\log _{10} t$. The transient part of the curve is seen to be approximated very well by a straight line. Using the slope of the line, Eq. (3), and the techniques described above, we calculate the effective permeability of the formation to be $3 \mathrm{md}$.

\subsubsection{Build-Up}

After producing the reservoir for $6 \times 10^{\prime} \mathrm{sec}$, the well was shut-in. The pressure build-up history in the first zone 
Zone 1 is a mass sink. At the outer boundary, pressure and energy fluxes are specified. There is no conduction nor convection at the other boundaries.

$\boldsymbol{n}$

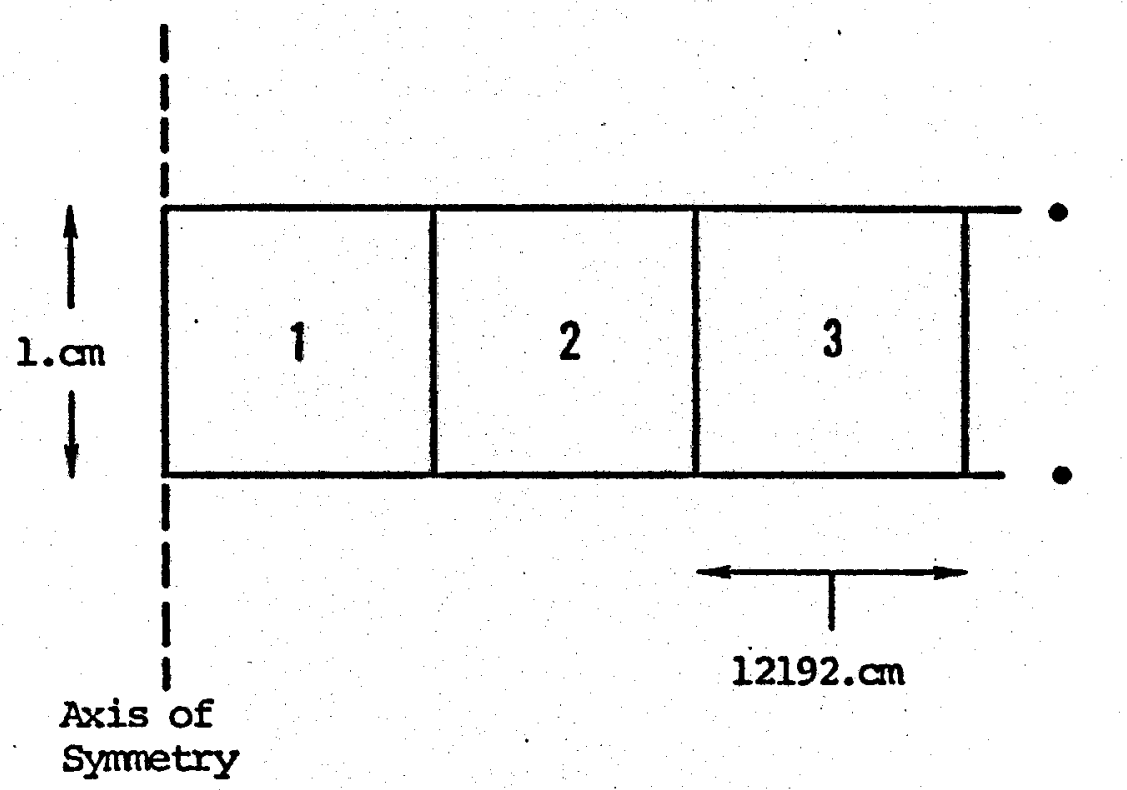

304800.cm

Gecmetry for one-dimensional axisymetric problems 


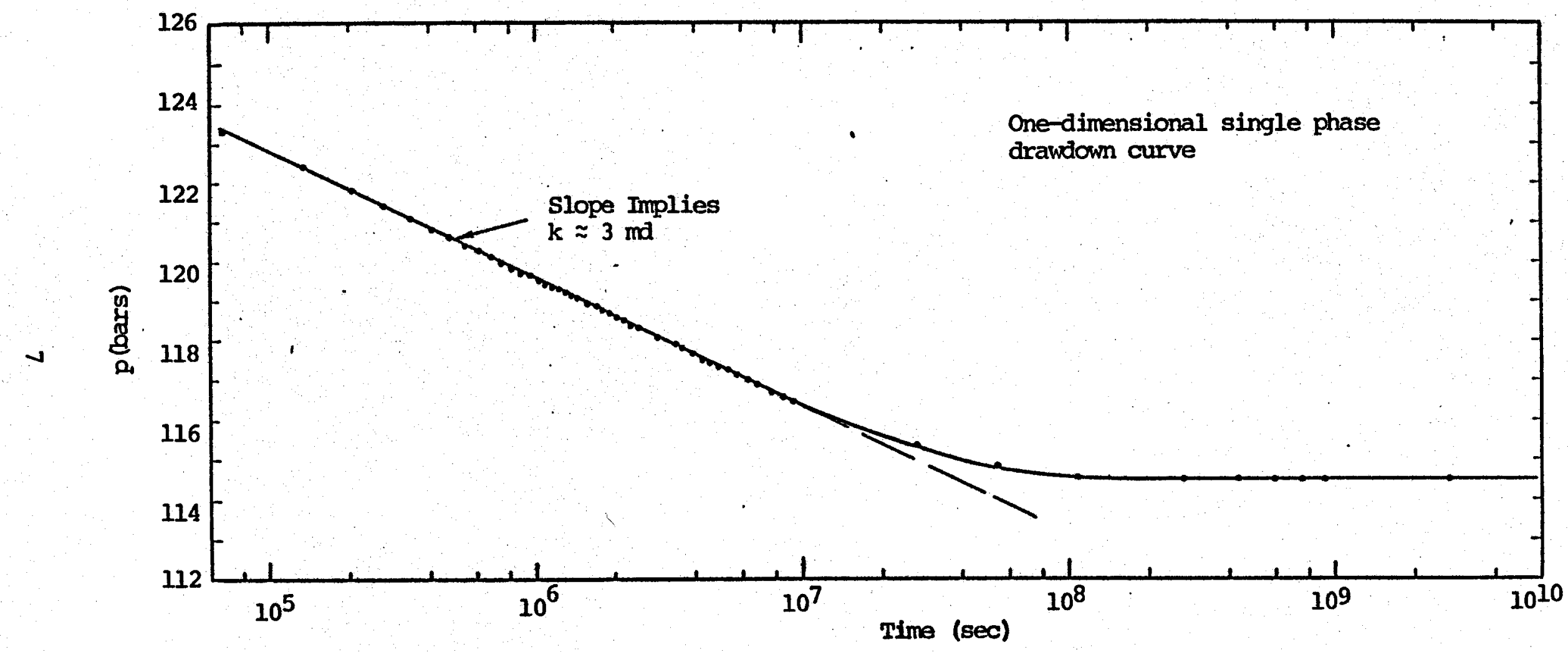

Figure 2 
was recorded and plotted versus $\log _{10}$ (shut-in time). This graph is presented in Fig. 3. Using theory analogous to the drawdown theory above, we find that the permeability calculated is about $3.3 \mathrm{md}$.

In both the drawdown and build-up analyses the calculated value of the permeability agrees very closely with the actual value of $3 \mathrm{md}$.

\subsection{EXAMPLE II. ONE-DIMENSIONAL, TWO PEASE}

\subsubsection{Drawdown}

Initial pressure of the reservoir $=124.98$ bars

Initial temperature of the reservoir $=599^{\circ} \mathrm{K}$

Mass sink production rate $=0.414 \mathrm{gm} / \mathrm{sec}$

The calculated pressure history of the sink zone versus $\log _{10} t$ is displayed by $F$ ig. 4. The best straight line approximation for early time behavior yields an effective permeability of $95.5 \mathrm{md}$. This is a dramatic variation from the actual value of $3.0 \mathrm{md}$.

\subsubsection{Build-Up}

The production was stopped at $4.2768 \times 10^{7} \mathrm{sec}$. The pressure build-up curve for the sink zone is plotted versus. $\log _{30}$ (shut-in time) in Fig. 5. From the graph, the calculated permeability is $6 \mathrm{md}$, a factor of 2 from the actual value. 


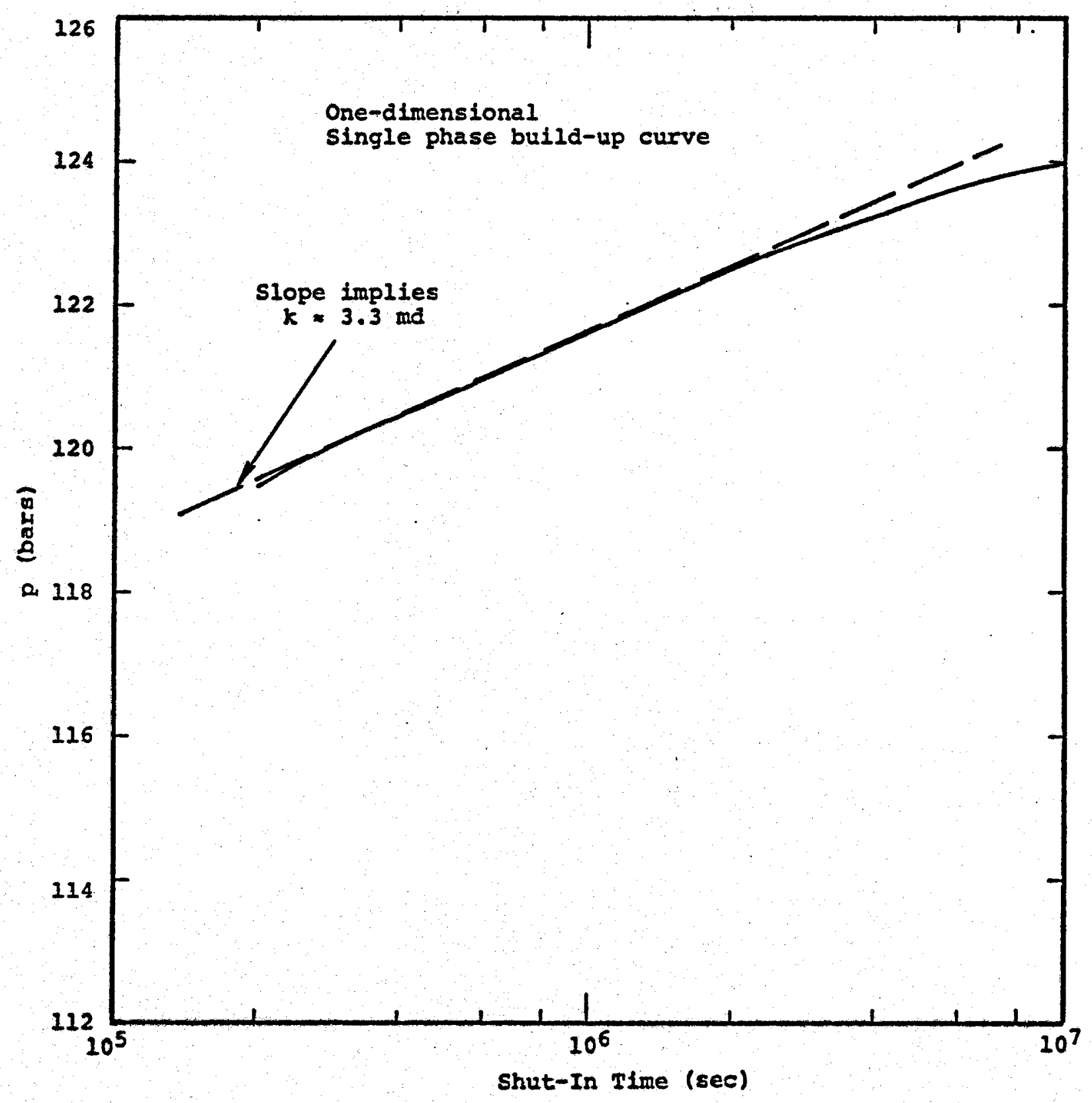

Figure 3 


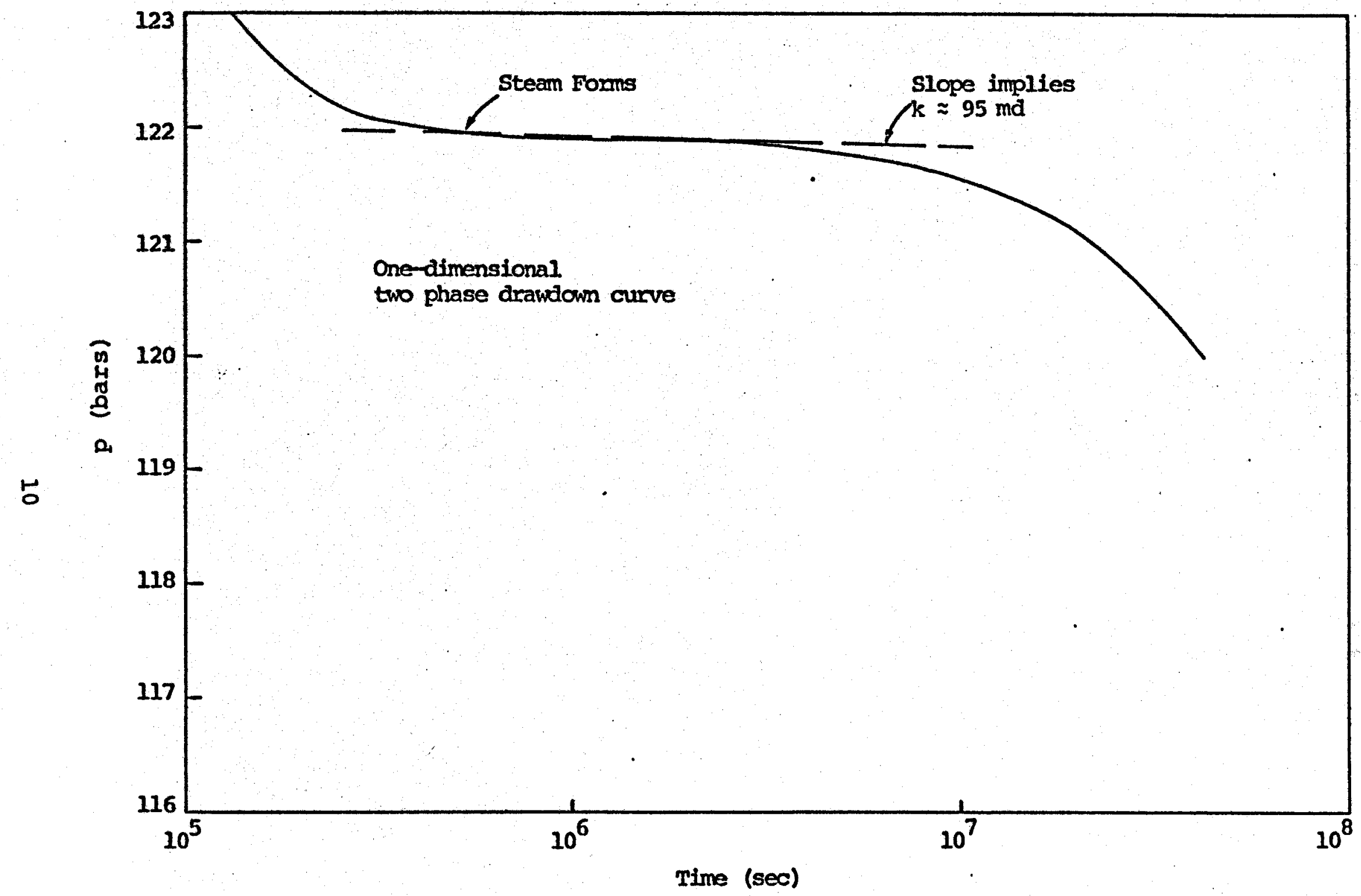

$\mathbb{D}$
1
$N$
$\infty$
$\mathbb{N}$
v

Figure 4 


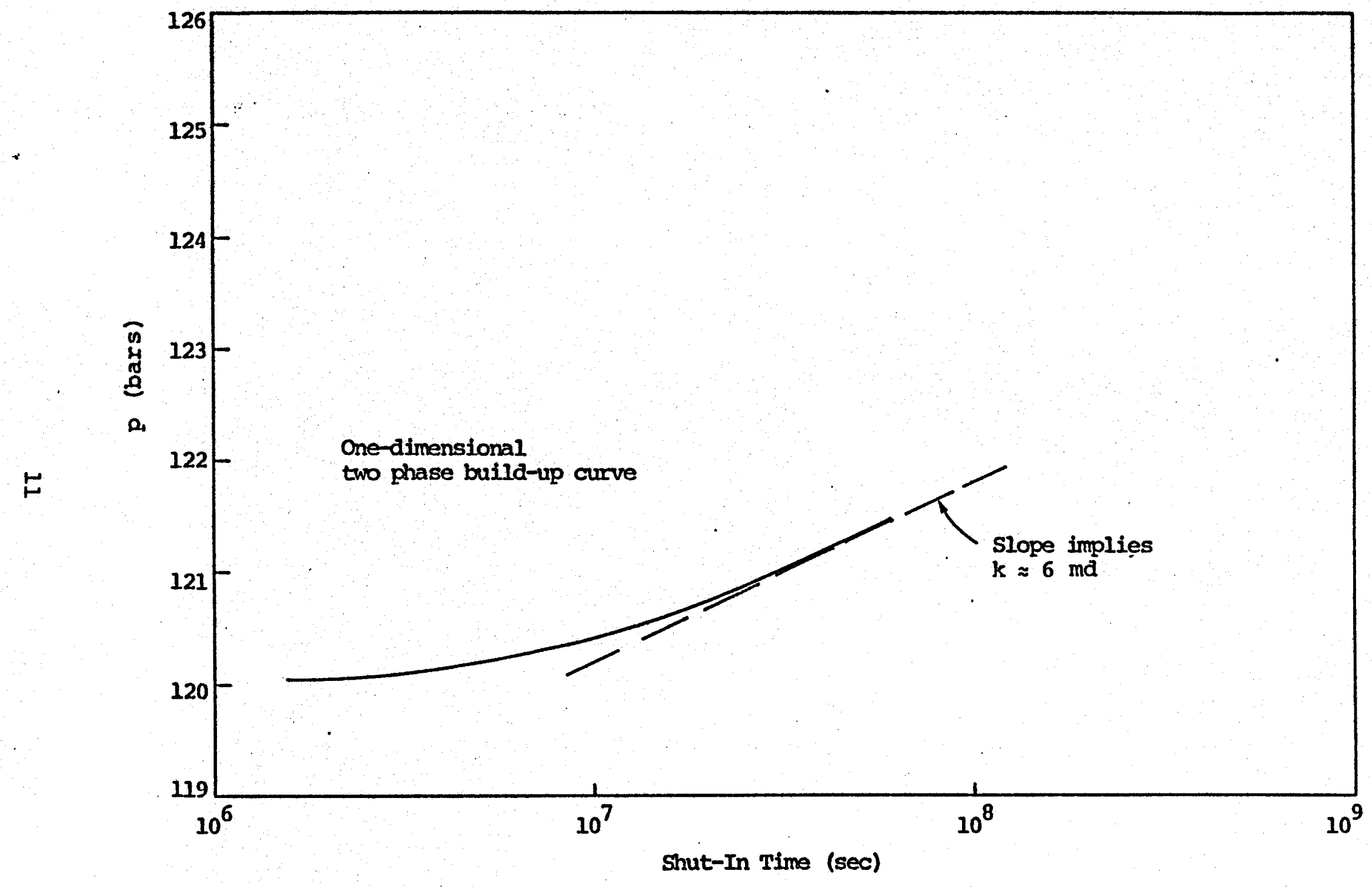

1
1
$N$
$\infty$
1
$v$

Figure 5 


\section{TWO-DIMENSIONAL EXAMPLES}

The examples below are two-dimensional axisymetric problems with 25 uniform horizontal zones and 5 uniform vertical zones (see Fig. 6). Pressure and energy fluxes are prescribed at the outer boundary. Gravity is assumed present in the vertical direction. The zone nearest the axis of symmetry in the top layer of the formation is a mass sink. This production zone corresponds to a $1 / 5$ penetration of the formation by a well. The rock properties used for these calculations are the same as those listed above for the one-dimensional problems.

Since the formation is only partially penetrated, a slight modification in the interpretation is necessary, as discussed by Nisle.* He indicates that the straight line used should approximate late time transient behavior on the drawdown and build-up curves.

\subsection{EXAMPLE I. TWO DIMENSIONS, SINGLE-PHASE}

\subsubsection{Drawdown}

Initial pressure in mass sink $=124.98$ bars

Initial temperature in mass sink $=586^{\circ} \mathrm{K}$

Mass sink production rate $=18,663.10 \mathrm{gm} / \mathrm{sec}$

Figure 7 is the plot of the drawdown pressure in the sink zone versus $\log _{10} t$. The straight line approximation to the curve implies a permeability of $2.96 \mathrm{md}$.

\section{1 .2 Buila-Up}

The well is shut-in at $1.33 \times 10^{\circ}$ seconds. The pressure history in the sink zone is given by Fig. 8. The slope of the line implies a permeability of $2.96 \mathrm{md}$.

*Nisle, R. G.. "The Effect of Partial Penetration on Pressure Build-Up in Oil Wells," Trans., AIME (1958), 213, 85. 


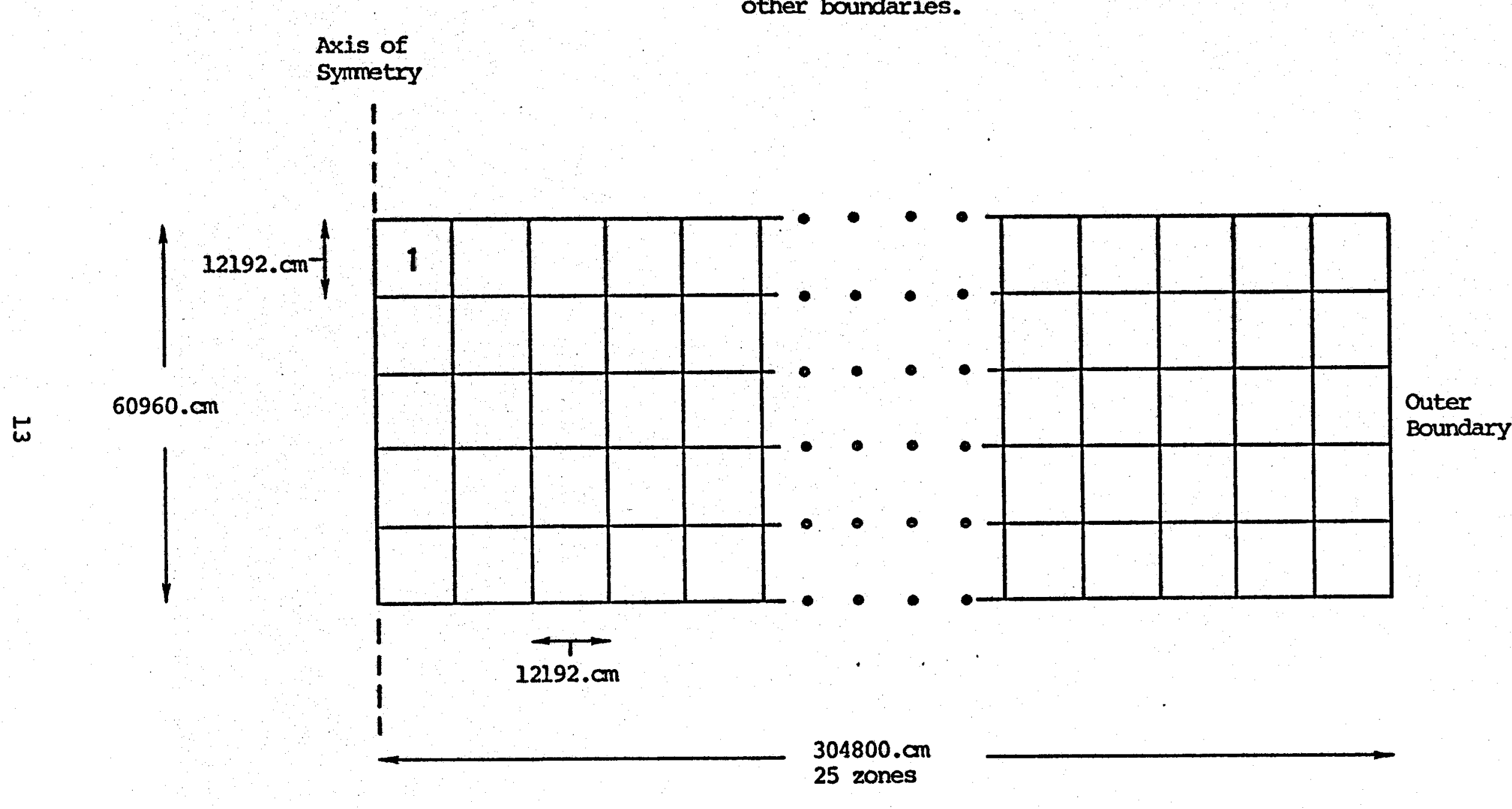

Zone 1 is a mass sink. At the outer boundary, pressure and energy fluxes are specified. There is no conduction nor convection at the other boundaries.

Axis of

Symmetry

25 zones

$N$
$N$
$N$
$\infty$
足

Gecmetry for two-dimensional axisymetric problems

Figure 6 


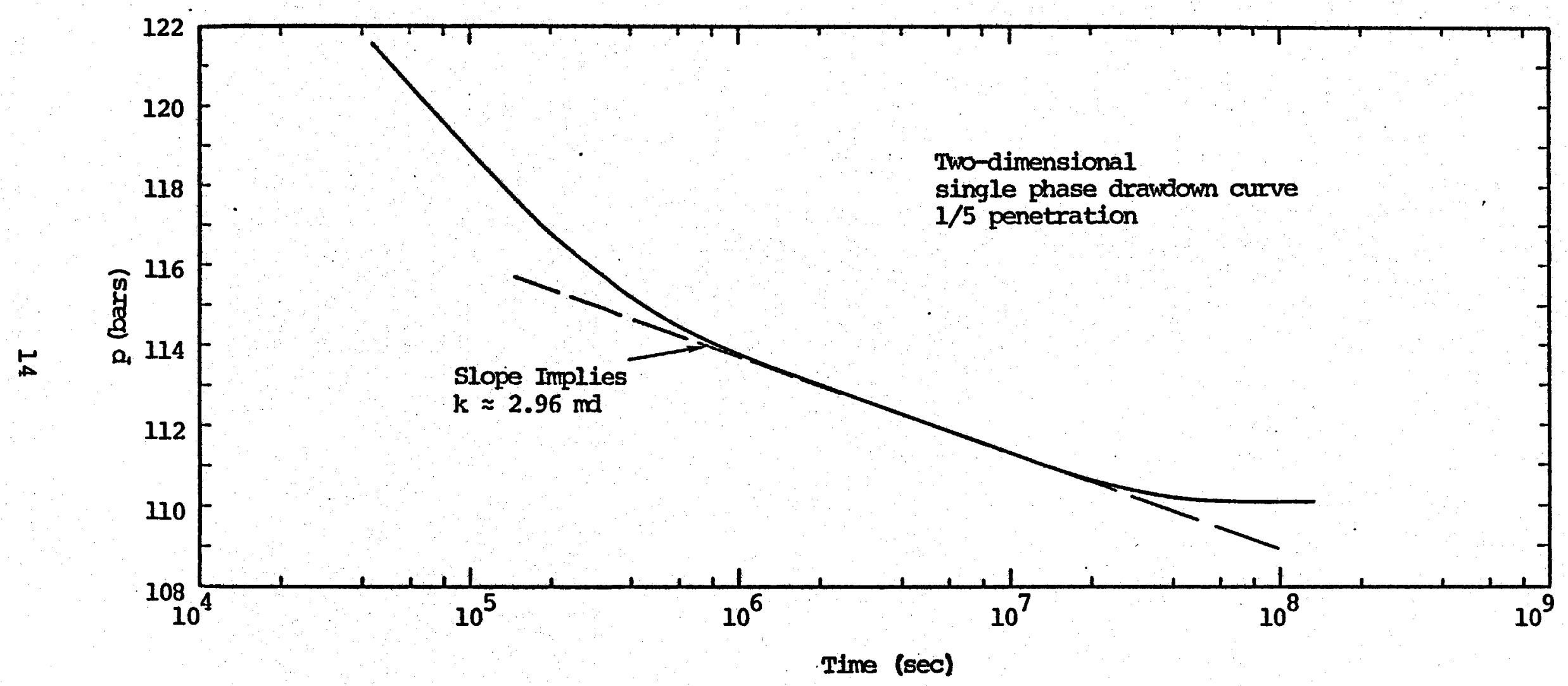

Figure 7 


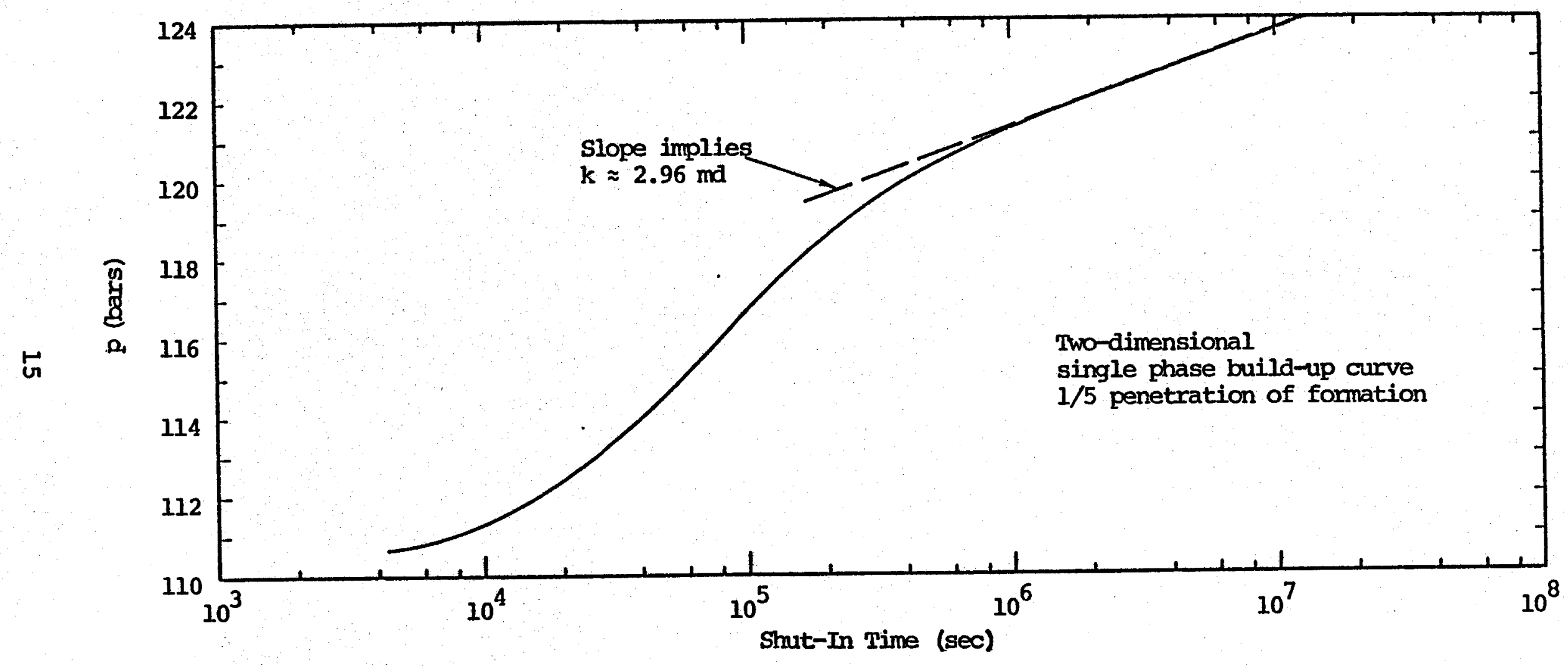

Figure 8 
The results of the classical interpretation for this two-dimensional, single-phase problem agree very well with the actual permeability of 3 md for the formation.

\subsection{EXAMPLE II: TWO DIMENSIONS, TWO PHASE}

\subsubsection{Drawdown}

Initial pressure in mass sink $=124.98$ bars

Initial temperature in mass sink $=599^{\circ} \mathrm{K}$

Mass sink production rate $=18,663.10 \mathrm{gm} / \mathrm{sec}$

During the drawdown of the reservoir, flashing occurs in the sink zone. The computed pressure history versus $\log _{10} t$ is given by Fig. 9. In the two-phase region of the graph, the calculated permeability for the formation is 19 ma. Again, this demonstrates that the classical interpretation breaks down when two phases are present.

\section{2 .2 Build-Up}

The well is shut-in at $1.62 \times 10^{7}$ seconds. The pressure history in the sink zone is given by Fig. 10. The slope of the best straight line for late build-up when two phases are still present implies a permeability of $5.2 \mathrm{md}$. Again, we see that this classical interpretation is inaccurate when there is multiphase flow in the reservoir. 


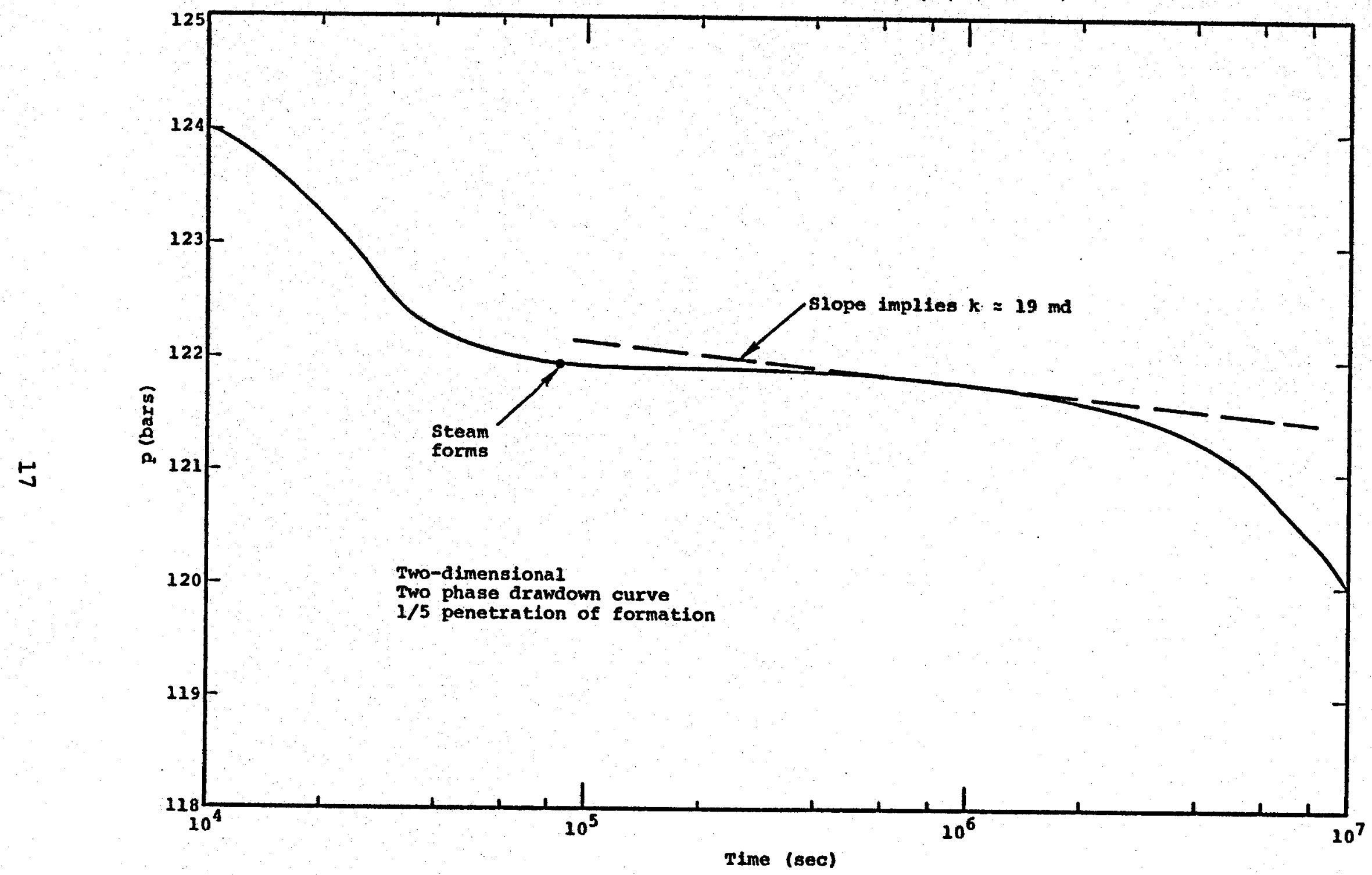

$D$
1
$N$
$\infty$
$心$

Figure 9 


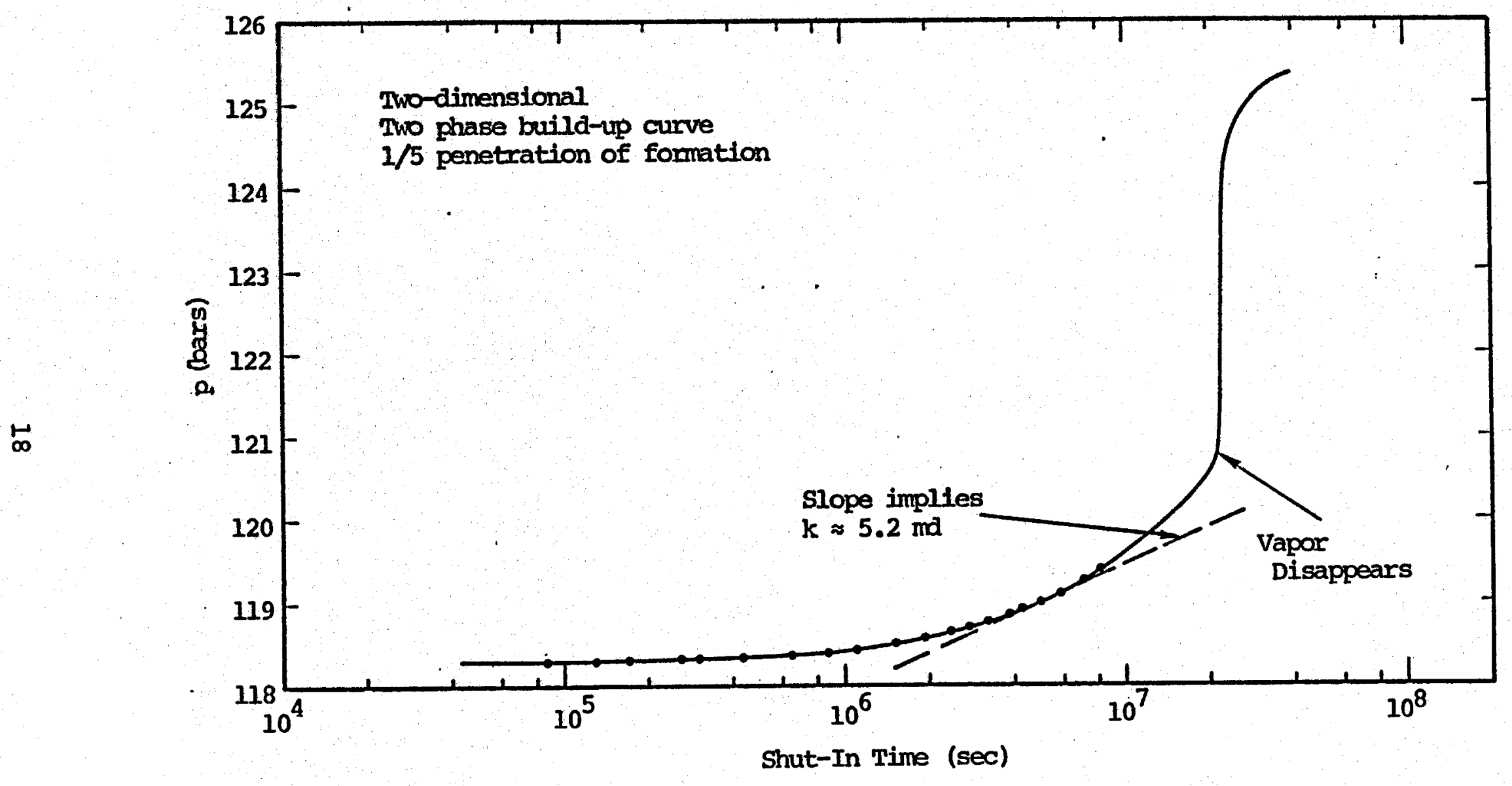

Figure 10 
IV. VAPOR BUOYANCY

During the pressure build-up in a two-phase multidimensional problem, we are also interested in determining if the vapor phase demonstrates buoyancy. Due to the coarse grid used in the above two-dimensional calculations, no buoyancy effect is seen since vapor exists in only one zone. In order to demonstrate the buoyancy of the vapor, a problem similar to the above-described two-dimensional problem was formulated in which a finer grid was used in the calculations. Figure 11 shows the refined grid. Note that there are only 14 horizontal grid blocks and 10 vertical blocks and that each of these "new" blocks is $1 / 16$ the size of the "old" calculational zones. The system is initially in hyorostatic equilibrium with a pressure of 121.89 bars in the top row of cells. The initial temperature of the system is $595^{\circ} \mathrm{K}$. The shaded region on Fig. 11 is the mass sink which produces at the rate of $18,663.1 \mathrm{gm} / \mathrm{sec}$. Drawdown of this system was continued until $t=4.32 \times 10^{7}$ seconds (500 days). At that time the production for the sink was terminated and the pressure was allowed to build up for $t=2.592 \times 10^{6}$ seconds ( 30 days). In order to show the buoyancy of the vapor phase, contour plots of the vapor saturations are presented in Figs. 12 through 17. The region shown is only the portion of the system where flashing occurred. The shaded area corresponds to the shaded mass sink of Fig. 11 . Figure 12 gives the vapor saturations at shut-in time. Figures 13 through 17 represent snapshots of the vapor distributions at 5 day increments during the build-up. At 30 days, the system has returned to all liquid phase. As is seen from these figures, the vapor phase does float to the upper layers of the reservoir. This is exactly the behavior we would expect to see during the actual pressure build-up. 
Axis of

Symmetry

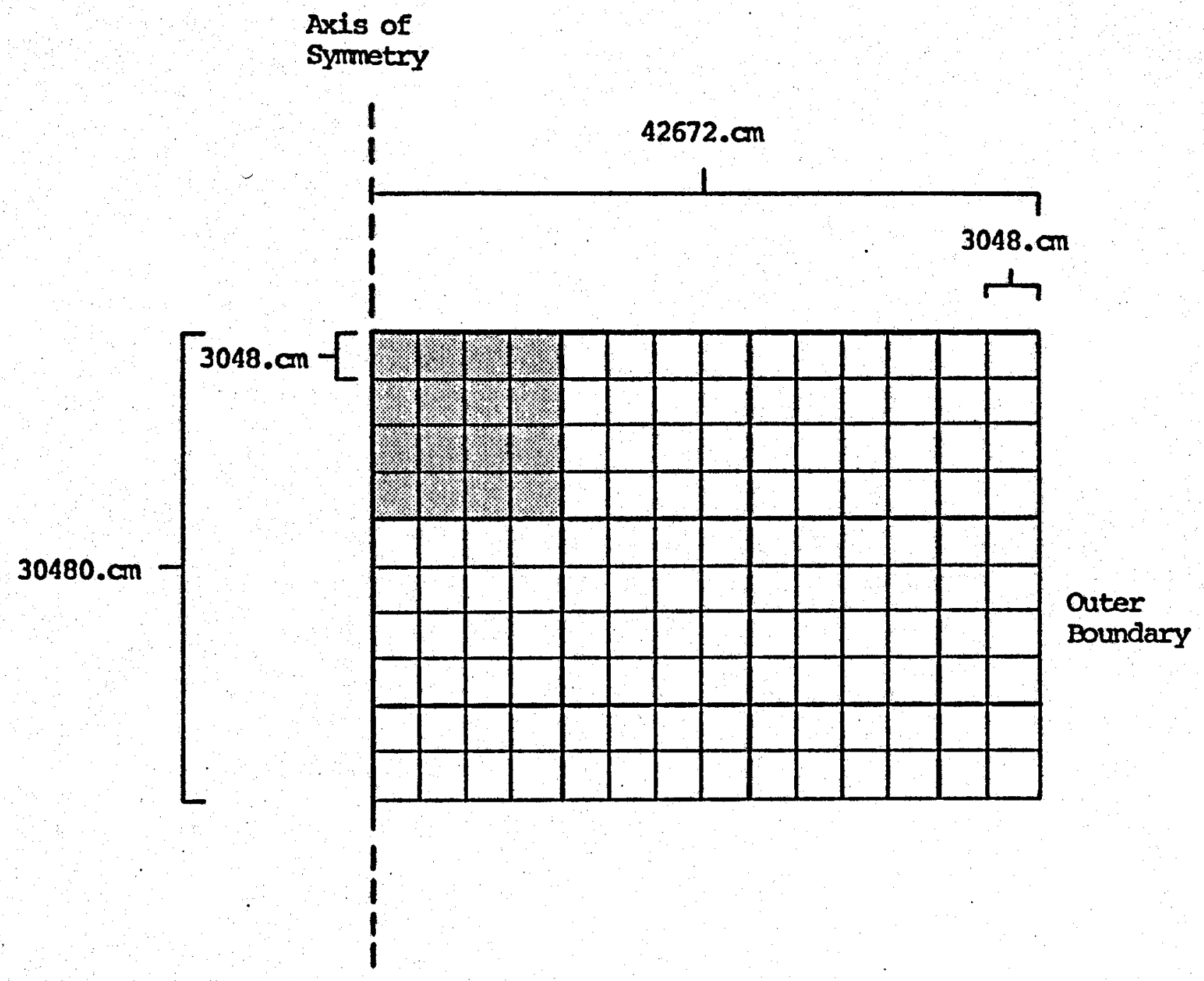

Heavy lines are "old" grid. Fine lines are "new" grid. Shaded region is the mass sink. At the outer boundary pressure and energy fluxes are specified. There is no convection nor conduction at the other boundaries.

Refined grid used to demonstrate vapor bouyancy during build-up

Figure 11 


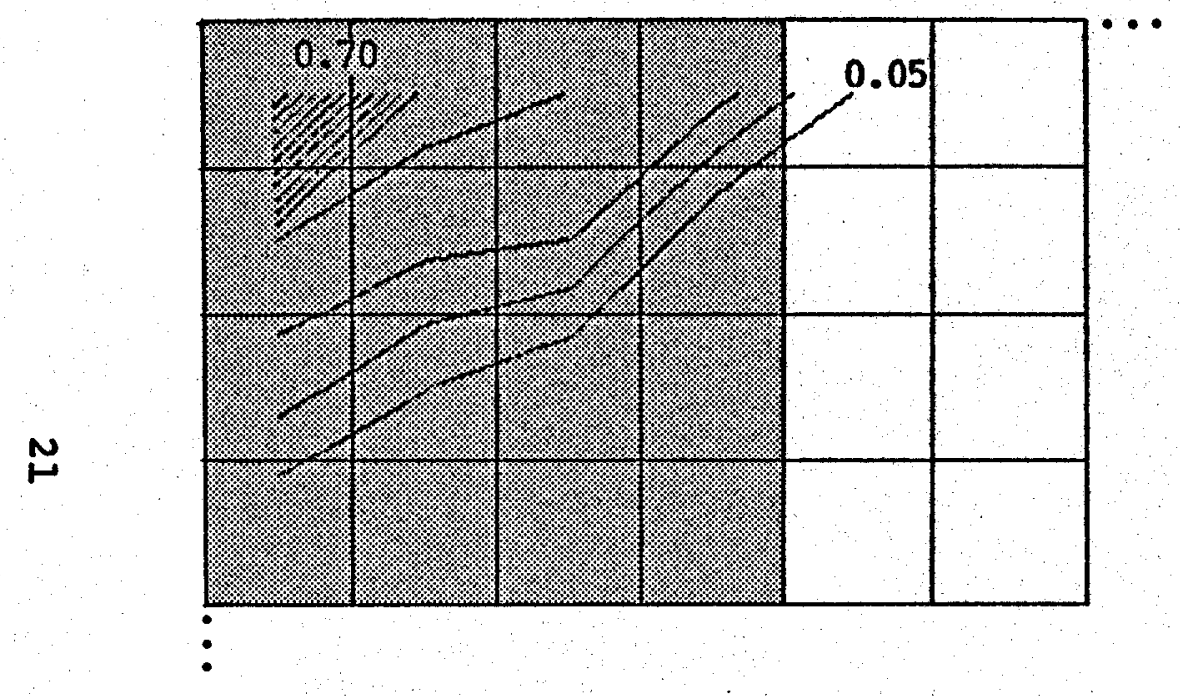

Figure 12

Vapor Saturation at Time of Shut-In

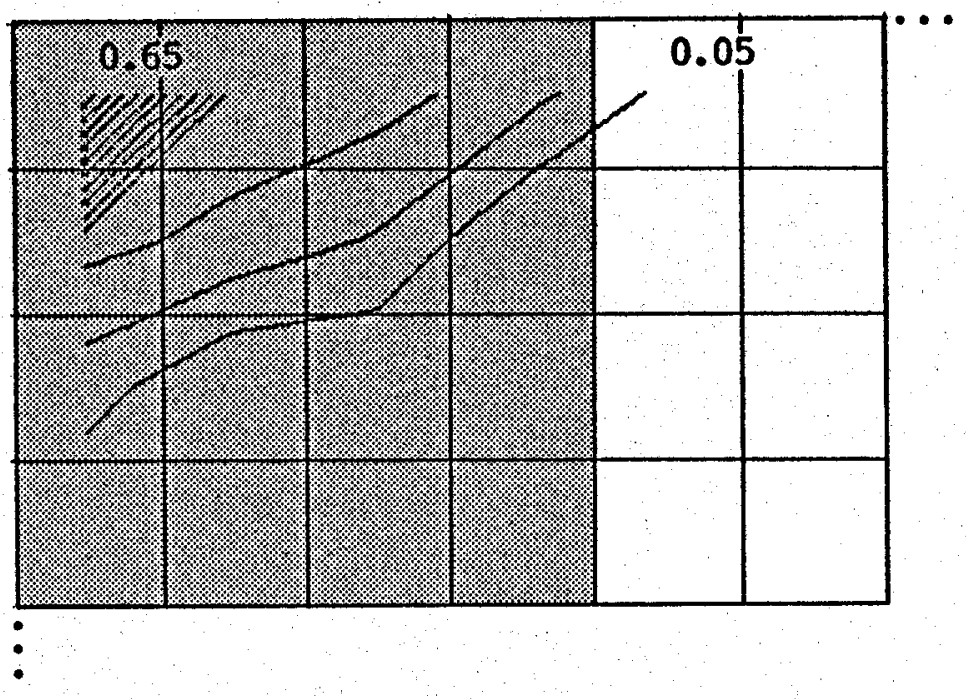

Figure 13

Vapor Saturation 5 Days After Shut-In 


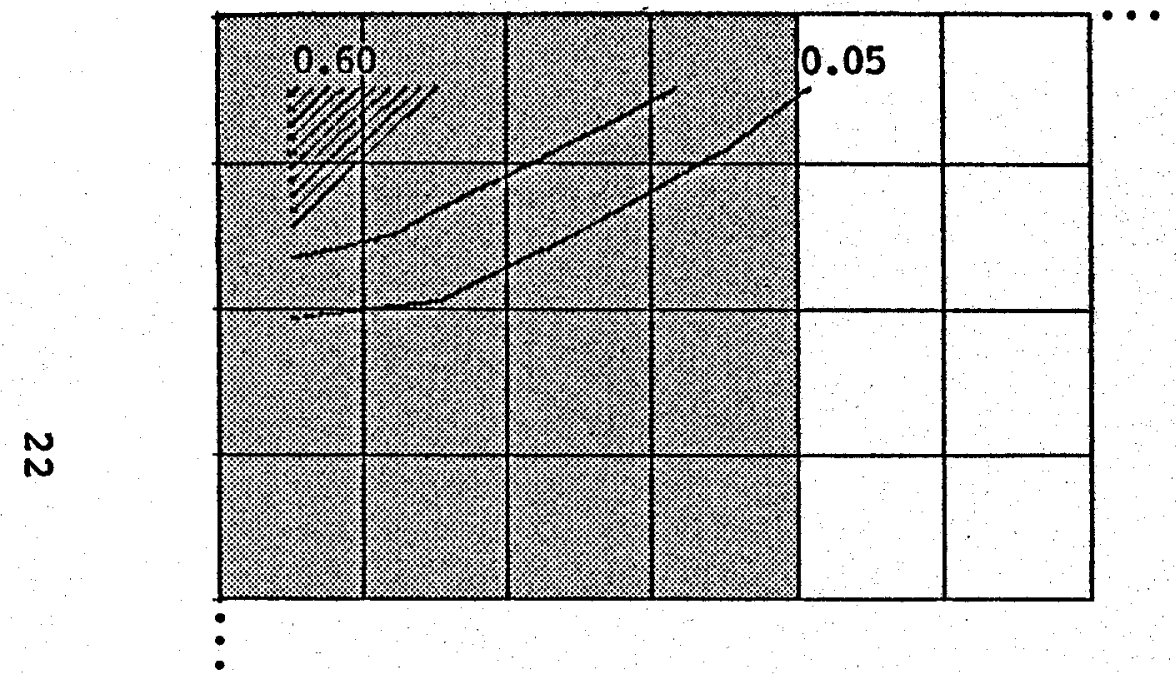

Figure 14

Vapor Saturation 10 Days After Shut-In

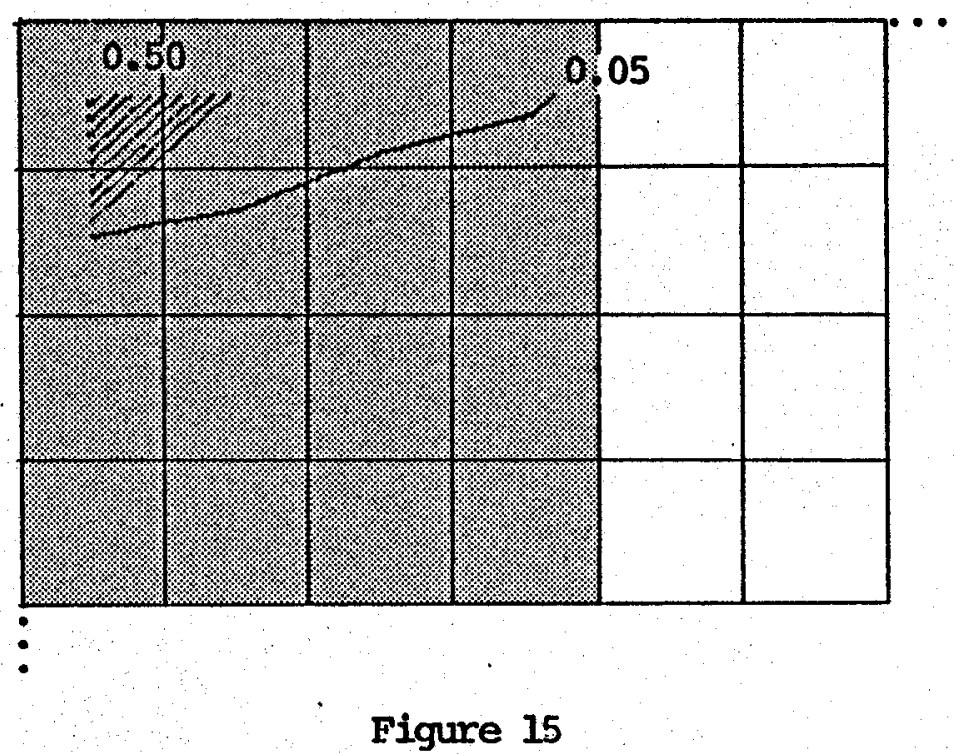

Vapor Saturation 15 Days After Shut-In 


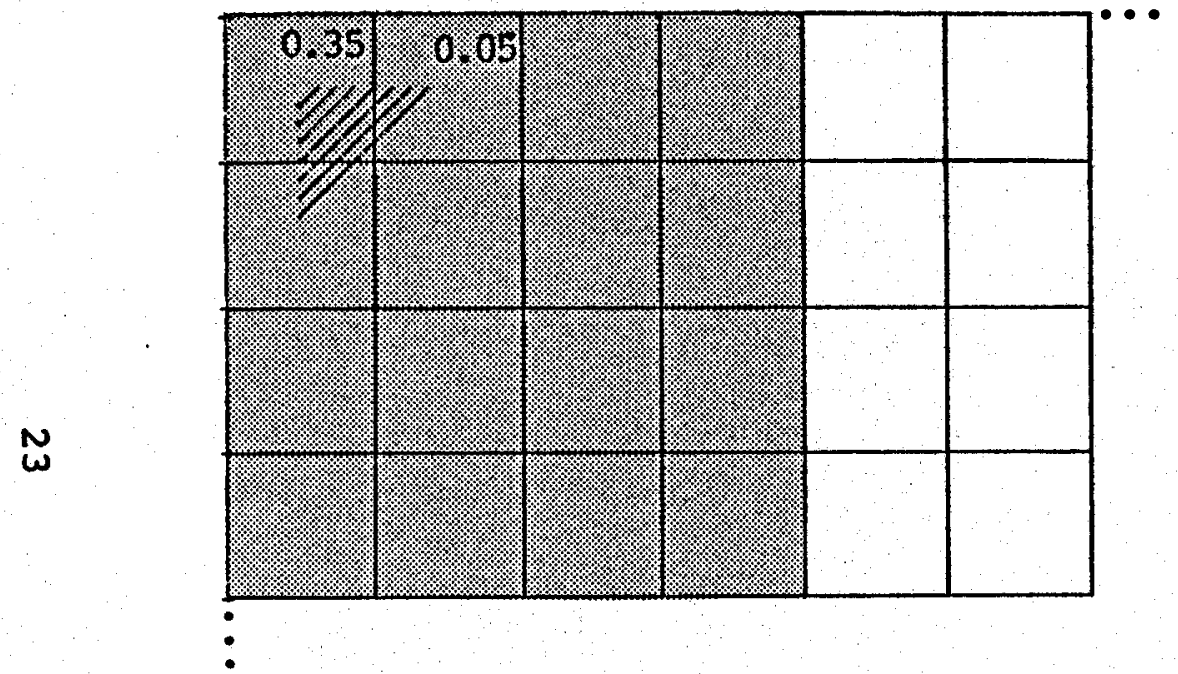

Figure 16

Vapor Saturation 20 Days After Shut-In

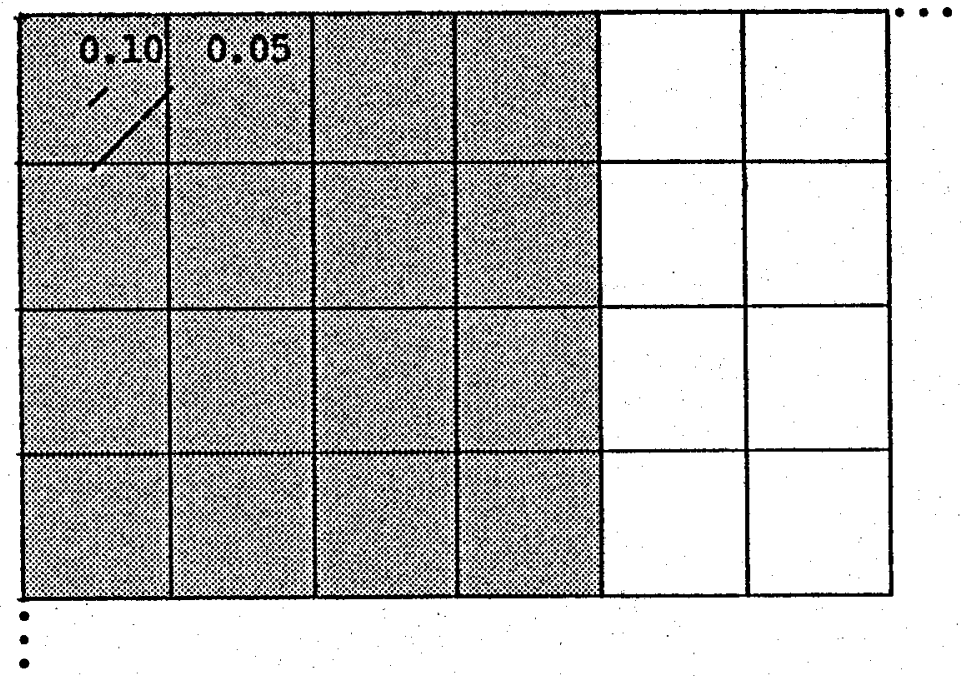

Figure 17

Vapor Saturation 25 Days After Shut-In 


\section{v. CONCLUSION}

The above results demonstrate that if only a single phase is present in the reservoir, the calculated behavior of the reservoir agrees very closely with the classical single-phase interpretation. However, if there is multiphase flow in the reservoir, the above results illustrate that this classical interpretation is no longer adequate to predict the reservoir behavior. Indeed this interpretation could lead to gross errors in the permeability data.

These results emphasize the need to use a simulator, such as QUAGMR, which has multiphase flow capabilities. By using such a simulator to model the productive history of a geothermal reservoir, a good appraisal of the reservoir can be obtained. As a predictive tool, the simulator is invaluable because it forces the computer to demonstrate how the reservoir will react to different engineering strategies, thus allowing the engineer to choose the strategy which will provide the best reservoir engineering management of the geothermal system. 